\title{
Coronary Angiography: Indications, Results and Cost-Effectiveness in the Diagnosis of Stable Angina Pectoris in Two Hospitals in Senegal
}

\author{
Paul Coffi Hessou1,2, Joseph Salvador Mingou ${ }^{2,3}$, Maboury Diao, ${ }^{2,3}$, Fatou Aw Leye ${ }^{2,3}$, \\ Bouna Diack $^{2,4}$, Alasane Mbaye ${ }^{2,4}$, Aliou Alassane Ngaïde ${ }^{2,4}$ \\ ${ }^{1}$ Laboratory of Physiology and Functional Physiological Explorations, Dakar, Senegal \\ ${ }^{2}$ Faculty of Medicine, Pharmacy and Odontology, Cheick Anta Diop University, Dakar, Senegal \\ ${ }^{3}$ Department of Cardiology, University Hospital Center Aristide le Dantec, Dakar, Senegal \\ ${ }^{4}$ Department of Cardiology, Idrissa Pouye General Hospital, Dakar, Senegal \\ Email: mingoujoseph@gmail.com
} Mouhamadou Bamba Ndiaye ${ }^{2,3}$, Simon Antoine Sarr ${ }^{2,3}$, Malick Bodian²,3, Papa Guirane Ndiaye ${ }^{2,3}$,

How to cite this paper: Hessou, P.C., Mingou, J.S., Diao, M., Aw Leye, F., Ndiaye, M.B., Sarr, S.A., Bodian, M., Ndiaye, P.G., Diack, B., Mbaye, A. and Ngaïde, A.A. (2021) Coronary Angiography: Indications, Results and Cost-Effectiveness in the Diagnosis of Stable Angina Pectoris in Two Hospitals in Senegal. World Journal of Cardiovascular Diseases, 11, 347-356. https://doi.org/10.4236/wjicd.2021.118034

Received: June 22, 2021

Accepted: August 10, 2021

Published: August 13, 2021

Copyright ( 2021 by author(s) and Scientific Research Publishing Inc. This work is licensed under the Creative Commons Attribution International License (CC BY 4.0).

http://creativecommons.org/licenses/by/4.0/ (c) (i) Open Access

\begin{abstract}
Background: The current gold standard for the diagnosis of stable coronary artery disease $(\mathrm{CAD})$ is invasive coronary angiography. But a large proportion of patients undergoing coronary angiography don't have obstructive coronary artery disease. Objective: The aim of the present study was to evaluate the diagnostic performance of invasive coronary angiography for patients without known coronary artery disease presenting with stable chest pain syndrome at two hospitals structures in Senegal. Method: We conducted a prospective, descriptive, and analytical study from March 1, 2019, to December 31, 2020 in the Cardiology Departments of General Hospital Idrissa Pouye (HOGIP) and Aristide Le Dantec Hospital (HALD). During the study period a cohort of patients referred to angiography coronary for diagnostic CAD because of suspected stable angina were enrolled. Demographic characteristics, risk factors, symptoms, and noninvasive test results were correlated with the presence of obstructive coronary artery disease. Results: A total of 143 patients were included in our study with a median age of $60.91 \pm 10.58$ years; men were $96(67.13 \%)$ and women $47(32.87 \%)$. The prevalence of hypertension was $60.84 \%$; diabetes was $34.27 \%$; dyslipidemia was $32.17 \%$ and sedentary was $26.57 \%$ in our study population. Typical and atypical angina symptoms were present in $37.76 \%(\mathrm{n}=54)$ and $49.65 \%(\mathrm{n}=71)$ respectively, while $10.49 \%$ had dyspnea. Coronary angiography revealed $59(41.26 \%)$ patients
\end{abstract}


with no CAD as well as $27(18.88 \%)$ with one-vessel; $28(19.58 \%)$ with two-vessel, and 29 (20.28\%) with three-vessel disease. Independent predictive factors for stable angina with the presence of obstructive lesion were: patient age (OR, 2.36; 95\% CI, 1.05 - 5.29; $\mathrm{p}=0.036)$; male gender $(\mathrm{OR}, 1.6$; 95\% CI, 0.72 - 3.57; $\mathrm{p}=0.24)$; diabetes (OR, 2.14; 95\% CI, $0.96-4.75 ; \mathrm{p}=0.06)$ and necrosis $\mathrm{Q}$ waves (4.75; CI, 0.98 - 23.09; $\mathrm{p}=0.05)$. Conclusion: In our study, more than half of the patients (58.74\%) referred for coronary angiography had a confirmed diagnosis. A better clinical and non-invasive assessment is needed to improve the efficiency of patient selection for coronary angiography.

\section{Keywords}

Stable Angina, Invasive Angiography, Diagnostic Efficacy, Senegal

\section{Introduction}

An accurate diagnosis is very important for appropriate treatment and estimation of prognosis in patients with ischemic heart disease. The current gold standard for the diagnosis of stable coronary artery disease (CAD) is invasive coronary angiography [1] [2].

However in the diagnostic approach to myocardial ischemia in stable angina pectoris, several registries or studies have shown that invasive angiographic procedure of some patients with abnormal noninvasive testing does not always reveal the presence of significant lesions on coronary angiography and it's sometimes susceptible to complications [2] [3] [4] [5].

For of all these observations, the practice of this examination is formalized by numerous recommendations of learned societies and relating to its indications, its relevance and possible results [2] [3].

Therefore, the current guidelines recommend for patients in stable clinical condition, invasive coronary angiography is only necessary in patients with suspected coronary artery disease in cases of inconclusive non-invasive testing or, exceptionally, in patients from particular professions, due to regulatory issues. However, invasive coronary angiography may be indicated if non-invasive assessment suggests high event risk for determination of options for revascularization [1].

In Senegal, particularly in Dakar, since the opening of cardiac catheterization rooms in cardiology departments, studies have been devoted to the assessment of coronary angiography and/or angioplasty in these departments. However, few studies have focused on a specific evaluation of coronary angiography in the diagnosis of stable chest pain [6] [7].

The purpose of this study was to evaluate the diagnostic efficiency of invasive coronary angiography in a cohort of patients with suspected stable angina.

Specifically, the aim was to determine the prevalence of patients with obstructive lesions on coronary angiography and to analyze the factors associated with 
the presence of CAD.

\section{Patients and Methods}

\subsection{Study Population}

This was an observational, descriptive, and analytical study conducted from March 1, 2019 to December 31, 2020 in the Cardiology departments of General Hospital Idrissa Pouye and Aristide Le Dantec Hospital in Dakar.

During the study period, one hundred forty-three $(n=143)$ patients with suspected stable angina or ischemic equivalent (exertional dyspnea, palpitations, blockpnea ...) after a noninvasive ischemic test and referred for coronary angiography were prospectively enrolled. All patients with a history of myocardial infarction, surgical or percutaneous myocardial revascularization had been excluded.

\subsection{Baseline Characteristics of Study Population}

The information on demographic characteristics, cardiovascular risk factors, symptoms, and noninvasive test results were collected before coronary angiography was performed. Angiographic data were collected from the electronic coronary angiography report. Some patients were contacted for additional information.

Symptoms were classified as typical angina, atypical chest pain, ischemic equivalent, or no symptoms. Typical angina was defined as 1) chest pain or substernal discomfort that is 2) caused by exertion or emotional stress and 3) relieved by rest and/or nitroglycerin. Atypical chest pain included patients with atypical angina (only two of the above criteria) and those with non-anginal chest pain (one or none of the above criteria). Ischemic equivalents were considered any collection of clinical signs (dyspnea, dizziness, arrhythmias, blockpnea).

The presence or absence of classical risk factors for coronary artery disease had been established from the patients' records. The suspicion of CAD was based on the presence and characteristics of chest pain symptoms and the presence of noninvasive test results (ECG, Exercise ECG, Echocardiography, Stress Echocardiography).

\subsection{Assessment of Angiographic CAD}

All patients underwent catheterization and coronary angiography according to the standard Judkin's technique. Angiograms were assessed in multiple projections by two experienced operators.

The obstructive coronary artery disease was defined as stenosis $\geq 70 \%$ in a major epicardial vessel or its branches, or $\geq 50 \%$ in the left main coronary artery, according to AHA recommendations [8].

According to angiographic findings, the study population was divided into two groups: patients with obstructive CAD (OCAD) and patients without ob- 
structive CAD (INOCA).

\subsection{Statistical Analysis}

Baseline demographics characteristics, risk factor for CAD, non-invasive tests results and angiographic findings were entered in SPSS version 16 for windows statistical Software and analyzed. All study variables were compared between patients with or without obstructive CAD. Means and standard deviations were used for quantitative variables; qualitative variables were assessed using proportions and frequencies. The Student's t test was used to compare the means; and the Chi2 test or Fischer's exact test was used to compare the proportions between the two groups. A p value $\leq 0.05$ in the univariate analysis was considered statistically significant. Multivariate analysis by logistic regression was used to identify the independent variables associated with the presence of significant lesions on coronary angiography.

\subsection{Ethical Aspects}

This study was approved by the Research Ethics Committee (REC) of Cheikh Anta Diop University of Dakar (Protocol Number 0407/2019/CER/UCAD).

\section{Results}

Between March 1, 2019, and December 31, 2020, 1137 coronary angiographies had been performed in the two Cardiology Departments. Our study had collated 143 patients who were referred for diagnostic coronary because of suspected stable coronary disease. This represented $12.58 \%$ of all patients referred for coronary angiography during this period.

\subsection{Baseline Characteristics of Patients}

The mean age of the patients was $60.91 \pm 10.58$ years; and $67.13 \%(\mathrm{n}=96)$ of patients were males and $32.87 \%(\mathrm{n}=47)$ females. The prevalence of hypertension was $60.84 \%$; diabetes was $34.27 \%$; dyslipidemia was $32.17 \%$ and sedentary was $26.57 \%$ of patients (Table 1 ).

Out of the patients referred for coronary angiography, $49.65 \%(n=71)$ had atypical angina; $37.76 \%(\mathrm{n}=54)$ had typical chest pain; $10.49 \%(\mathrm{n}=15)$ had dyspnea, and only one patient had non-anginal chest pain.

All of the patients had been submitted to a non-invasive diagnostic before coronary angiography. The most frequent tests performed were the resting electrocardiogram (100\%) and the resting echocardiography (88.81\%) of the patients. Exercise ECG and stress Echocardiography were performed in 24 (16.78\%) and 15 (10.49\%) patients respectively (Table 2). The most observed abnormalities of the non-invasive tests were: $\mathrm{ST}$ sub-shift, negative $\mathrm{T}$ waves and necrosis $\mathrm{Q}$ waves with $23.1 \%(\mathrm{n}=33) ; 24.48 \%(\mathrm{n}=35)$ and $10.49 \%(\mathrm{n}=15)$ respectively. Hypokinesia was the most significant segmental kinetic disorder with a prevalence of $22.38 \%(n=32)$. 
Table 1. Demographic and clinical characteristics of study population.

\begin{tabular}{|c|c|c|}
\hline Variables & $\mathrm{n}=143$ & $\%$ \\
\hline Age (mean; years) & \multicolumn{2}{|c|}{$60.91 \pm 10.58$} \\
\hline Female gender & 47 & 32.87 \\
\hline Male gender & 96 & 67.13 \\
\hline Smoking & 7 & 4.89 \\
\hline Obesity & 15 & 10.49 \\
\hline Diabetes & 49 & 34.27 \\
\hline Hypertension & 87 & 60.84 \\
\hline Dyslipidemia & 46 & 32.16 \\
\hline Sedentarily & 38 & 26.57 \\
\hline Non-anginal chest pain & 1 & 0.70 \\
\hline Typical angina & 54 & 37.76 \\
\hline Atypical chest pain & 71 & 49.65 \\
\hline Dyspnea & 15 & 10.49 \\
\hline Dyspnea and atypical chest pain & 2 & 1.4 \\
\hline
\end{tabular}

Table 2. Paraclinical data of the patients.

\begin{tabular}{ccc}
\hline Variables & $\mathrm{N}=143$ & $\%$ \\
\hline Exercise Electrocardiogram & 24 & 16.78 \\
Stress Echocardiography & 15 & 10.49 \\
Resting Electrocardiogram & 143 & 100 \\
Resting Echocardiography & 127 & 88.81 \\
\hline
\end{tabular}

\subsection{Prevalence of Stable Angina with Significant Obstructive Lesions}

Out of the 143 patients, $59(41.26 \%)$ had normal coronary arteries and 84 (58.74\%) had obstructive CAD. Among these patients, $18.88 \%(\mathrm{n}=27)$ had single-vessel disease; $19.58 \%(n=28)$ had two-vessel disease; and $20.28 \%(n=29)$ had three-vessel disease lesions.

\subsection{Predictive Factors for Obstructive Coronary Artery Disease}

The univariate analysis showed 5 variables significantly associated ( $\mathrm{p} \leq 0.05$ ) with the presence of obstructive CAD: age, male gender, diabetes, presence of typical angina, and necrotizing $\mathrm{Q}$ waves. The mean age of patients with OCAD was $63.36 \pm 9.10$ years and $57.31 \pm 12.73$ years for INOCA patients group $(\mathrm{p}=$ $0.004)$; out of 84 patients with OCAD, male was $63(75 \%)$ and female was 21 (25\%).

The prevalence of diabetic patients with OCAD (41.67\%) was higher than those with INOCA (23.73\%; $p=0.026)$; sedentarity (OR, 1.10; CI 95\% 0.52 - 
2.35; $\mathrm{p}=0.84)$ was associated with a greater probability of obstructive CAD, but without statistical significance. The other risk factors like hypertension, dyslipidemia, obesity and smoking did not show a significant difference between the two groups.

According to the symptom, typical chest pain was observed more frequently $(46.42 \%)$ in patients with OCAD as compared to patients with INOCA $(25.42 \%)$; $\mathrm{p}=0.011$.

In comparison of abnormal result related to non-invasive tests in the two groups, the difference was not statistically significant. However Q wave of necrosis prevalence is more important in patients with OCAD than patients with INOCA (15.47\%/3.38\%; p = 0.025) (Table 3).

In multivariate analysis, age $(\mathrm{OR}, 2.36 ; 95 \% \mathrm{CI}, 1.05$ - 5.29; $\mathrm{p}=0.036)$; male gender (OR, 1.60; 95\% CI, 0.72 - 3.57; $\mathrm{p}=0.24)$, diabetes $(\mathrm{OR}, 2.14 ; 95 \% \mathrm{CI}, 0.96$ - 4.75; $\mathrm{p}=0.06$ ), and necrosis $\mathrm{Q}$ waves (4.75; CI, 0.98 - 23.09; p = 0.05) were shown to be independent predictors of obstructive CAD, but without statistical significance (Table 4).

Table 3. Results of the univariate analysis.

\begin{tabular}{|c|c|c|c|c|c|}
\hline Variables & $\begin{array}{l}\text { No Obstructive } \\
\text { coronary artery disease }\end{array}$ & $\begin{array}{l}\text { Obstructive coronary } \\
\text { artery disease }\end{array}$ & OR & CI $(95 \%)$ & p-value \\
\hline Mean age (years) & $57.31 \pm 12.73$ & $63.36 \pm 9.10$ & 1.04 & $1.01-1.08$ & 0.004 \\
\hline $\mathrm{F}$ & $26(44.07 \%)$ & $21(25 \%)$ & \multirow{2}{*}{2.36} & \multirow{2}{*}{$1.15-4.82$} & \multirow{2}{*}{0.017} \\
\hline M & $33(55.93 \%)$ & $63(75 \%)$ & & & \\
\hline Obesity & $7(11.86 \%)$ & $8(9.52 \%)$ & 1.27 & $0.43-3.74$ & 0.78 \\
\hline Diabetes & $14(23.73 \%)$ & $35(41.67 \%)$ & 0.43 & $0.207-0.91$ & 0.026 \\
\hline Hypertension & $35(59.32 \%)$ & $52(61.90 \%)$ & 0.89 & $0.45-1.77$ & 0.75 \\
\hline Dyslipidemia & $18(30.50 \%)$ & $28(33.34 \%)$ & 0.87 & $0.42-1.79$ & 0.85 \\
\hline Smoking & $2(3.38 \%)$ & $5(5.95 \%)$ & 0.55 & $0.10-2.95$ & 0.70 \\
\hline Sedentarily & $15(25.42 \%)$ & $23(27.38 \%)$ & 1.10 & $0.52-2.35$ & 0.84 \\
\hline Typical angina & $15(25.42 \%)$ & $39(46.42 \%)$ & 0.39 & $0.19-0.81$ & 0.011 \\
\hline Atypical chest pain & $34(57.62 \%)$ & $37(44.05 \%)$ & 1.72 & $0.88-3.38$ & 0.12 \\
\hline Dyspnea & $8(13.56 \%)$ & $7(8.34 \%)$ & 1.72 & $0.58-5.05$ & 0.40 \\
\hline Exercise $\mathrm{ECG}^{\star}$ & $12(20.34 \%)$ & $11(13.1 \%)$ & 1.69 & $0.69-4.15$ & 0.23 \\
\hline Stress Echocardiography ${ }^{\star}$ & $8(13.56 \%)$ & $6(7.1 \%)$ & 1.75 & $0.55-5.50$ & 0.20 \\
\hline Resting Electrocardiogram* & $38(64.40 \%)$ & $57(67.85 \%)$ & 0.82 & $0.40-1.67$ & 0.60 \\
\hline Resting echocardiography & $15(25.42 \%)$ & $23(27.38 \%)$ & 0.83 & $0.38-1.81$ & 0.62 \\
\hline ST-segment subshift & $18(30.50 \%)$ & $17(20.24 \%)$ & 0.49 & $0.22-1.08$ & 0.10 \\
\hline Negative T waves & $14(23.72 \%)$ & $21(25 \%)$ & 1.07 & $0.49-2.33$ & 0.96 \\
\hline Q waves of necrosis & $2(3.38 \%)$ & $13(15.47 \%)$ & 5.21 & $1.31-24.07$ & 0.025 \\
\hline Hypokinesia & $16(27.11 \%)$ & $16(19.04 \%)$ & 0.63 & $0.28-1.39$ & 0.30 \\
\hline
\end{tabular}

*For the non-invasive tests comparison we have only considered the patients with positive tests. 
Table 4. Results of the multivariate analysis.

\begin{tabular}{cccc}
\hline Variables & OR & IC 95\% & Valeur $\mathbf{p}$ \\
\hline age & 2.36 & $1.05-5.29$ & 0.036 \\
Male gender & 1.60 & $0.72-3.57$ & 0.24 \\
Diabetes & 2.14 & $0.96-4.75$ & 0.06 \\
Typical angina & 0.48 & $0.21-1.06$ & 0.70 \\
Necrosis Q waves & 4.75 & $0.98-23.09$ & 0.05 \\
\hline
\end{tabular}

\section{Discussion}

A large proportion of patients undergoing invasive angiography because angina and evidence myocardial ischemia do not have obstructive CAD, more common in women than men, and a large proportion have INOCA as a cause of their symptoms [3] [9]. The diagnostic accuracy of coronary angiography can be improved by identifying the important factors for the prediction of obstructive CAD.

In our study, twenty months data of 143 patients undergoing non-invasive tests for stable chest pain diagnosis followed by coronary angiography have been presented.

The current study showed 84 (58.74) patients with obstructive coronary artery disease. This prevalence is different from the one observed in other studies which showed a low percentage of obstructive CAD among their patients. It's was $16.5 \% ; 23.8 \% ; 27.4 \%$ in series observed respectively in Germany, Brazil and Korea [10] [11] [12].

However, the results observed in different studies are not always comparable because of the definitions used for significant lesions and the inclusion criteria. Tessa et al. evaluated the angiographic profile of 405 patients and found a predictive value of $75 \%$. But coronary artery disease with obstructive lesions was defined as a lesion with stenosis $\geq 50 \%$ in one (1) or more vessels ( $\geq 2 \mathrm{~mm}$ in diameter) [13]. In a cohort of 686 consecutive patients undergoing diagnostic coronary angiography for suspected CAD, Nakas et al. showed that $45.92 \%$ had obstructive coronary artery disease. In this study, existence of significant CAD was defined as $\geq 50 \%$ stenosis in the lumen/internal diameter of at least one coronary artery or $\geq 30 \%$ for the left main coronary artery [14].

In the current study we further tried to elucidate the risk factors predicting obstructive CAD in patients with stable chest pain. We have observed that age, male gender, and typical angina symptoms were predictive for having obstructive CAD. This finding was consistent with other studies results [10] [11] [14]. Our study also showed that only diabetes was associated with a higher prevalence of obstructive CAD. Other risks factor as hypertension, dyslipidemia, and smoking were not. These findings contrast with the results showed by other investigators who observed that traditional risk factors were associated with a higher prevalence of obstructive CAD [9] [11]. 
Among patients who had prior noninvasive tests before invasive coronary angiography, results of noninvasive tests predict obstructive CAD. However in the current study it was noticed that abnormalities in non-invasive tests were not correlated with obstructive CAD, except $\mathrm{Q}$ waves of necrosis. This suggests that these tests have minimal incremental value beyond clinical factors in predicting obstructive disease [4].

In this observational study we found that $58.74 \%$ of the patients without history of CAD obstructive stenosis were documented in the angiography. This results in $41.26 \%$ without significant obstructive CAD as a possible reason for their angina pectoris symptoms. Other studies and registries had shown higher rates of patients with stable angina but without obstructive lesions with values ranging from $50 \%$ to more than $70 \%$ [3] [11] [12].

All these results show that the underlying etiology of angina is not obstructive coronary artery disease only. This is clinically relevant and indeed shows that other pathologies may be the cause of angina. In this case, angina symptoms may have a limited ability to provide prediction on the presence and extent of angiographic CAD [14].

Studies carried out in the past two decades have highlighted that coronary and epicardial microvascular dysfunction (CMD) and epicardial vasospam, alone or in combinaison with coronary artery disease, are adjunctive mechanisms of myocardial ischemia [3] [15] [16].

Some authors have reported that epicardial spasms as well as microvascular dysfunction are a common finding in patients presenting with stable angina pectoris and positive ischemic stress test when no obstructive CAD is present [10] [15].

In our study no distinct tests were performed to research the underlying etiology of angina chest pain in the absence of obstructive CAD, because it was an observational cross-sectional study only. It is therefore to envisage prospective controlled trials in patients with angina pectoris since many clinicians may attribute angina pectoris in these patients to non-cardiac reasons only after CAD is excluded invasively.

\section{Limitation of the Study}

1) The association of stable chest pain with the presence and extent of coronary atherosclerotic lesions could be influenced by several factors including parameters like assessment of pretest probability and clinical likelihood of CAD following the latest recommendations of European Society of Cardiology guidelines for the diagnosis and management of chronic coronary syndromes. These factors were not considered in the current study.

2) The rate of patients with ischemic stress tests was relatively low. Non-cardiac reasons for angina in patients without a positive test might influence the results.

3) Pretest probability and the different modalities of non-invasive tests result in lower overall costs and enhanced effectiveness. For this purpose it would have 
been useful to determine in our study the cost-effectiveness of the most widely available diagnostic evaluation strategies for individuals without known CAD presenting with stable chest pain syndrome.

These three points are a major weakness of this study.

4) The study population was only 143 patients who underwent coronary angiography. All patients with stable chest pain and abnormalities in non-invasive test could not be included in the study. It's an invasive and expensive procedure. Otherwise we would have a larger cohort with more meaningful data for variable analysis.

\section{Conclusion}

The present study has shown that $58.74 \%$ of patients referred for coronary angiography had a confirmed diagnosis and $41.26 \%$ had ischemia without obstructive CAD. These results are important for daily clinical practice in the diagnosis since chest pain might be caused by other diseases and not only by obstructive CAD. So a better clinical and noninvasive assessment is needed to improve the efficiency of patient selection for this invasive procedure.

\section{Conflicts of Interest}

The authors declare no conflicts of interest regarding the publication of this paper.

\section{References}

[1] Knuuti, J., Wijns, W., Saraste, A., Capodanno, D., Barbato, E., Funck-Brentano, C., et al. (2020) ESC Scientific Document Group, 2019 ESC Guidelines for the Diagnosis and Management of Chronic Coronary Syndromes: The Task Force for the Diagnosis and Management of Chronic Coronary Syndromes of the European Society of Cardiology (ESC). European Heart Journal, 41, 407-477. https://doi.org/10.1093/eurheartj/ehz425

[2] Gach, O., Davin, L., Lempereur, M., Marechal, P., Martinez, C. and Lancellotti, P. (2019) Coronarographie Diagnostique. Revue Medicale de Liege, 74, 17-21.

[3] Vijay, K., Alaide, C., Paolo, G., Berry, C., Escaned, J., Maas, A.H.E.M., et al. (2020) An EAPCI Expert Consensus Document on Ischemia with Non-Obstructive Coronary Arteries in Collaboration with European Society of Cardiology Working Group on Coronary Pathophysiology \& Microcirculation Endorsed by Coronary Vasomotor Disorders International Study Group. Special Article. EuroIntervention, 16, 1049-1069. https://doi.org/10.4244/eijy20m07 01

[4] Borren, N., Mass, A.H. and Ottervanger, J.P. (2015) Stop Invasive Coronary Angiography as the Gold Standard for the Diagnosis of Stable Angina. Interventional Cardiology, 7, 1-4.

[5] Konst, R.E., Meeder, J.G., Wittekoek, M.E., Maas, A.H.E.M., Appelman, Y., Piek, J.J., et al. (2020) Ischemia with No Obstructive Coronary Arteries. Netherlands Heart Journal, 28, 66-72. https://doi.org/10.1007/s12471-020-01451-9

[6] Fatou, A.W., Ndiaye, M.B., Mbow, T., Bodian, M., Sarr, S.A., Mingou, J., et al. (2019) Apport des explorations non invasives et résultats de la coronarographie dans l'angor stable au service de cardiologie du CHU Aristide le Dantec de Dakar. 
Revue Africaine de Médecine Interne, 6, 27-32.

[7] Aw, F., Ndiaye, M.B., Diop, C., Sarr, S., Mingou, J., Diouf, M., et al. (2020) Place of Exercise Echocardiography in Stable Coronary Artery Disease in Sub-Saharan Africa: A Series in Senegal. World Journal of Cardiovascular Diseases, 10, 19-29. https://doi.org/10.4236/wjcd.2020.101003

[8] Weintraub, W.S., Karlsberg, R.P., Tcheng, J.E., Boris, J.R., Buxton, A.E., Dove, J.T., et al. (2011) ACCF/AHA 2011 Key Data Elements and Definitions of a Base Cardiovascular Vocabulary for Electronic Health Records: A Report of the American College of Cardiology Foundation/American Heart Association Task Force on Clinical Data Standards. Journal of the American College of Cardiology, 58, 202-222. https://doi.org/10.1016/j.jacc.2011.05.001

[9] Reeh, J., Therming, C.B., Heitmann, M., Højberg, S., Sørum, C., Bech, J., et al. (2019) Prediction of Obstructive Coronary Disease and Prognosis in Patients with Stable Angina. European Heart Journal, 40, 1426-1435. https://doi.org/10.1093/eurheartj/ehy806

[10] Westermann, D., Savvatis, K., Wollenberg, U., Limberg, R., Maier, L.S. and Bauersachs, J. (2015) Prevalence of Obstructive Coronary Artery Disease in Ambulatory Patients with Stable Angina Pectoris. Journal of Clinical and Experimental Cardiology, 6, Article No. 387.

[11] Costa Filho, F.F., Chaves, Á.J., Ligabó, L.T., dos Santos, E.M., da Silva, D.T., Puzzi, M.A., et al. (2015) Efficacy of Patient Selection for Diagnostic Coronary Angiography in Suspected Coronary Artery Disease. Arquivos Brasileiros de Cardiologia, 105, 466-471. https://doi.org/10.5935/abc.20150099

[12] Cho, D.-H., Choi, J., Mi-Na, K., Kim, H.-L., Kim, Y.H., Na, J.O., et al. (2020) Gender Differences in the Presentation of Chest Pain in Obstructive Coronary Artery Disease: Results from the Korean Women's Chest Pain Registry. The Korean Journal of Internal Medicine, 35, 582-592. https://doi.org/10.3904/kjim.2018.320

[13] Genders, T.S.S., Coles, A., Hoffmann, U., Patel, M.R., Mark, D.B., Lee, K.L., et al. (2018) The External Validity of Prediction Models for the Diagnosis of Obstructive Coronary Artery Disease in Patients with Stable Chest Pain Insights from the PROMISE Trial. ACC: Cardiovascular Imaging, 11, 437-446.

https://doi.org/10.1016/j.jcmg.2017.02.020

[14] Nakas, G., Bechlioulis, A., Marini, A., Vakalis, K., Bougiakli, M., Giannitsi, S., et al. (2019) The Importance of Characteristics of Angina Symptoms for the Prediction of Coronary Artery Disease in a Cohort of Stable Patients in the Modern Era. Hellenic Journal of Cardiology, 11, 241-246. https://doi.org/10.1016/j.hjc.2018.06.003

[15] Konst, R.E., Damman, P., Pelligrini, D., van Royen, N., Maas, A.H.E.M. and Elias-Smale, S.E., et al. (2021) Diagnosis Approach in Patients with Angina and No Obstructive Coronary Artery Disease: Emphasing the Role of Coronary Test. Netherlands Heart Journal, 29, 121-128.

https://doi.org/10.1007/s12471-020-01532-9

[16] Konst, R.E., Damman, P., Pelligrini, D., Hartzema-Meijer, M.J., van Uden, B.J.C., Jansen, T.P.J., et al. (2021) Vasomotor Dysfunction in Patients' with Angina and Nonobstructive Coronary Artery Disease Is Dominated by Vasospam. International Journal of Cardiology, 333, 14-20. https://doi.org/10.1016/j.ijcard.2021.02.079 